\title{
La producción y consumo de contenidos de redes sociales por las audiencias de medios digitales
}

\section{The production and consumption of social media contents by digital media audiences}

\author{
Dra. Samia Benaissa Pedriza \\ Universidad Complutense de Madrid \\ samia.benaissa@ucm.es \\ ORCID: https://orcid.org/0000-0002-1708-3338
}

Resumen: En un contexto informativo amenazado por el auge de las fake news y caracterizado por la creciente pérdida de confianza de los lectores, se emprende una investigación que pretende descubrir el valor informativo que ostentan los contenidos de redes sociales consumidos por las audiencias de la prensa digital. El estudio analiza de forma cuantitativa la producción y el consumo de este tipo de contenidos en las noticias más leídas por la audiencia de cuatro diarios digitales (EI País, EI Mundo, La Vanguardia y ABC). El estudio comparativo analiza, mediante un análisis de contenido, los productos informativos publicados en las ediciones online de la prensa digital, excluyendo los publicitados en las propias redes. El análisis practicado revela que la audiencia consume informaciones elaboradas con fuentes de información tradicionales frente a contenidos de redes sociales en una proporción de tres a uno. Entre semana, el consumo de piezas informativas que incluyen contenidos de redes sociales es moderado. Los lectores solo leen una media de 2,5 noticias al día, una cifra que incluso desciende los fines de semana. Las áreas temáticas de las noticias más visitadas se asocian a las soft news y el género más común es la noticia en el $70 \%$ de los casos. Los resultados del estudio, exploratorio e inédito, estarían indicando el limitado valor de los contenidos de redes sociales como fuente de información alternativa a las tradicionales.

Abstract: The present research is undertaken in an information context threatened by the rise of fake news and characterized by a declining confidence of the audience in media organizations. The investigation aims at discovering which is the informative value of the social media contents consumed by the audience of the digital press. The research quantitatively analyzes the production and consumption of social media contents in the news most read by the audience of four digital newspapers (El País, El Mundo, La Vanguardia and ABC). The comparative study analyzes information products published in online editions of the digital press, excluding the ones publicized in social media. The content analysis practiced reveals that the audience prefers to consume 
information elaborated with traditional news sources instead of social media contents in a ratio of three to one. During the week, the consumption of news that include social media contents is moderate. Readers only read an average of 2.5 news per day, a figure that even drops on weekends. The thematic areas of the news most read are associated with soft news and the journalistic genre most read is news in $70 \%$ of the cases. The results of the study, exploratory and innovative, would be confirming the limited value of social media contents as an alternative news source, compared to traditional sources of information.

Palabras clave: Audiencias digitales, fuentes de información, géneros periodísticos, prensa digital, redes sociales

Keywords: Digital audiences, digital media, journalistic genres, news sources, social media

\section{PRESENTACIÓN, ESTADO DE LA CUESTIÓN Y JUSTIFICACIÓN}

La presencia de un número mayor de operadores en el ecosistema informativo y el auge de las redes sociales como canales alternativos de comunicación ha generado grandes expectativas respecto a los nuevos consumos de información periodística. Sin embargo, a pesar de que las redes sociales son un canal cada vez más consultado por los públicos para informarse, lo cierto es que siguen siendo aún una opción minoritaria. Los últimos estudios publicados (Nielsen y Schrøder, 2014: 472-489; VaraMiguel et al., 2017) revelan que la audiencia sigue informándose mayoritariamente por vías tradicionales (televisión, prensa escrita y prensa digital). $\mathrm{Y}$ el grado de confianza que los públicos depositan en los medios de comunicación social también es superior. Quizás por ello las redes sociales están intentando replicar la apariencia de los diarios tradicionales para generar mayor credibilidad (Sundar, 2008: 58-74), seleccionando y presentando informaciones según la teoría del gatekeeping (Shoemaker y Vos, 2009: 7589). Los medios, por su lado, también han incorporado modos de presentar la información característicos de las redes sociales, así como contenidos que son utilizados como fuentes de información alternativas en su producción informativa.

La gran mayoría de estudios académicos han analizado el comportamiento de la audiencia cuando consume información de medios de comunicación publicada en redes sociales (Stassen, 2010: 116-131; Pew Research Center, 2012; Pew Research Center, 2017). Pero no abundan las investigaciones que examinen ni la producción, ni el consumo de información, respecto a informaciones de medios digitales elaboradas con contenidos de redes sociales. El consumo de estos contenidos fuera de las propias redes no ha suscitado el interés mayoritario de la doctrina, a pesar de que la audiencia sigue confiando más en los medios online para informarse con rigor y combatir el auge de las noticias falsas o fake news (AMI, 2017).

Este desconocimiento ocasiona un desajuste entre la producción informativa de los medios y el consumo efectivo de los públicos. En la actualidad, son comunes los análisis estadísticos llevados a cabo por los medios mediante herramientas como Google Analytics, Chartbeat o Parse.ly para intentar descubrir cuáles son las preferencias de la audiencia. Pero los análisis se centran más en el consumo estratificado de audiencias diferenciadas en razón de variables 
como la edad, el sexo o la procedencia geográfica, entre otras muchas. Se miden las noticias más compartidas o más comentadas en las redes sociales o el número de lectores que acceden a la información alojada en las páginas web de los diarios en función del tipo de dispositivo (móviles, tablets, portátiles o apps). No incluyen, por tanto, un análisis de las reacciones de la audiencia globalmente considerada, que es la más numerosa y la que consume las noticias de mayor relevancia informativa del día.

Conocer cuál es el consumo efectivo de noticias que incluyen contenidos de redes sociales como fuentes informativas por las audiencias de medios digitales permitiría mejorar la calidad de la producción periodística actual, empleando los recursos más eficaces para generar una mayor credibilidad y confianza entre los lectores. En ese sentido, la investigación que se presenta aporta datos agregados sobre la producción de este tipo de contenidos consumidos por las audiencias de los diarios digitales de información general más leídos en España. El análisis se basa en métricas que, en términos de audiencias, pueden ser calificadas como de rendimiento, ya que toman en cuenta el número de visitas por noticia (o page views) en el cómputo de las informaciones más leídas cada día.

El trabajo de investigación se justifica por desarrollar tanto un análisis global, como un estudio comparativo entre medios inédito hasta la fecha, que permitirá ampliar el escaso conocimiento actual sobre la producción y el consumo de contenidos informativos procedentes de redes sociales en la prensa digital española.

\section{REVISIÓN TEÓRICA}

A nivel académico, existen algunas investigaciones que analizan la presencia de contenidos de redes sociales en la prensa escrita. Paulussen y Harder (2014, 542-551) descubrieron que solo un pequeño porcentaje $(35 \%)$ de las informaciones incluían contenidos generados por los usuarios de las redes sociales y solo el $13,5 \%$ de ellas habían sido elaboradas de forma exclusiva con este tipo de fuentes. Broersma y Graham (2013: 446-464) descubrieron que redes sociales como Facebook, Twitter y YouTube eran utilizadas de forma regular como fuentes de información en la prensa escrita tanto en hard news como en soft news. Por su parte, Nielsen y Schrøder (2014: 472-489) comprobaron que los periódicos eran considerados fuentes de información más relevantes que las redes sociales y Masip et al. (2015: 363-370) comprobaron que los contenidos de los medios escritos generaban una mayor confianza entre la audiencia.

En la prensa digital, apenas se han publicado investigaciones que analicen la producción de noticias que incorporan contenidos de redes sociales. Herrero (2013: 453-470) analizó el uso de contenidos procedentes de redes sociales en las noticias sobre un caso de sucesos (la desaparición de la adolescente Marta del Castillo) publicadas por la prensa digital española. Descubrió que el $80 \%$ de las noticias incluían contenidos generados por usuarios de redes sociales.

Lasorsa, Lewis y Holton (2012: 19-36) observaron que las prácticas periodísticas se veían afectadas cuando se manejaban contenidos de redes sociales como herramientas informativas y que las noticias eran elaboradas teniendo en cuenta 
las dinámicas comunicativas de Twitter. En el mismo sentido se pronuncia Diezhandino (2012) sobre los cambios que está experimentando el sistema de fuentes.

Otros estudios (García de Torres et al., 2011: 611620; Cobos, 2010) analizaron el valor informativo de Twitter como fuente, en consonancia con los hallazgos de Campos (2008: 287-293), Noguera (2010: 176186) y Herrera y Requejo (2011: 149-182) sobre el incremento del uso de esta red social para consumir información de medios de comunicación.

Nölleke et al. (2017:1) insisten en el desajuste existente entre el uso de los contenidos de redes sociales realizado por los periodistas y las preferencias reales de la audiencia. Comprobaron que a pesar de que los contenidos de redes sociales eran ampliamente incluidos en las noticias de deportes, estas apenas suscitaban el interés de los lectores de diarios digitales.

Las áreas temáticas asociadas a esta categoría de informaciones se han analizado desde el punto de vista de la prensa escrita. Broersma y Graham (2013: 453-455) verificaron que el $43 \%$ de las noticias que incluían contenidos de redes sociales (tuits en el caso concreto) hacian referencia a temas propios de soft news. Respecto a la prensa digital, no se han localizado estudios empíricos específicos, aunque Aguirre (2007:13) advierte de los cambios en la producción informativa de los medios provocados por las nuevas preferencias temáticas de la audiencia. En ese sentido, es significativo el estudio publicado por la Asociación de Medios de Información sobre el consumo más superficial de contenidos informativos de redes sociales en relación con los de medios digitales (AMI, 2017).
La producción de contenidos de redes sociales también se ha examinado en relación con los géneros periodísticos. Pero la mayoría de investigaciones solo han analizado los géneros de las informaciones publicadas por los medios digitales en las redes sociales (García-Avilés y Arias, 2016: 101-132; Ríos, 2014). En Twitter se categorizaron varios géneros nuevos que Ríos (2014) calificó como "última hora, fotonoticia, fotogalería, narración en directo, minivídeos, revista de prensa, análisis y making of". El único estudio que aborda específicamente el tratamiento de los contenidos de redes sociales en noticias publicadas por medios digitales en sus ediciones online es el practicado por Herrero (2013: 453-470). Este reveló que en la información de sucesos, el género de la noticia era el más habitual para elaborar informaciones con fuentes procedentes de redes sociales (Herrero, 2013: 460). Otro estudio (Bacallao, 2010: 114-125) también analizó la presencia de los contenidos de redes sociales en las informaciones de la prensa escrita e igualmente comprobó que las noticias eran el género discursivo predominante frente a los reportajes, los editoriales y las entrevistas.

El escaso número de investigaciones publicadas sobre la producción y consumo de contenidos de redes sociales en los medios digitales convierte a la presente investigación en un estudio de carácter exploratorio que tomará como punto de referencia las fuentes de información procedentes de las redes sociales más utilizadas por los usuarios (Twitter, Facebook, YouTube e Instagram). 


\section{OBJETIVOS E HIPÓTESIS}

El propósito de la presente investigación es ampliar el conocimiento sobre la producción y consumo de contenidos de redes sociales efectuado por las audiencias de los principales diarios digitales de información general en España.

Los objetivos concretos de la investigación son conocer el volumen de contenidos de redes sociales que consume la audiencia en las ediciones online de los diarios digitales más leídos en España, así como descubrir en qué áreas informativas y géneros periodísticos se emplea con mayor frecuencia este tipo concreto de fuentes de información.

Las hipótesis de la investigación están estrechamente relacionadas con sus objetivos y son las siguientes:

$\mathrm{H} 1$. Las audiencias de los medios online consumen contenidos informativos de redes sociales de forma moderada

$H 2$. Las áreas temáticas que incluyen más contenidos informativos de redes sociales son propias de las soft news

H3. Los géneros periodísticos que incorporan contenidos informativos de redes sociales con mayor frecuencia son de naturaleza eminentemente informativa

\section{METODOLOGÍA}

La investigación recurrió al método cuantitativo para llevar a cabo el análisis de variables. La técnica de investigación utilizada fue el análisis de contenido practicado sobre una muestra de informaciones publicadas por los cuatro diarios digitales de información general más leídos en España a principio del año 2018.
Las fuentes de la investigación fueron siempre primarias y estuvieron constituidas por las piezas informativas editadas por los diarios de referencia. Las informaciones se extrajeron del ranquin de las 10 noticias más leídas del día, publicadas en las ediciones online de cada medio. Se analizó por tanto la producción informativa de los medios digitales publicada en sus respectivas páginas web y no en las redes sociales.

La muestra, de naturaleza no probabilística, estuvo formada por el total de noticias elaboradas con contenidos de redes sociales como fuentes de información publicadas durante el período de estudio en ese ranquin (204 noticias). La delimitación temporal fue de 21 días comprendidos entre el 8 y el 28 de enero de 2018.

Las noticias fueron registradas diariamente mediante un sistema de acceso electrónico efectuado a la misma hora (21:00) para evitar sesgos en el análisis de variables. El instrumento empleado para seleccionar la muestra es de fácil manejo y además facilita la recuperación de la información en todo momento a través de las direcciones web de cada pieza informativa, lo que favorece la réplica del estudio.

Las noticias procedieron de una muestra más amplia de 840 piezas incluidas en el listado de las noticias más leídas por las audiencias de los diarios analizados en la investigación. Estos se eligieron en función de su mayor capacidad de difusión según los últimos datos proporcionados por Comscore (octubre de 2017), el medidor de audiencias digitales empleado como referencia. La audiencia conjunta de los cuatro medios más leídos en España reunió un total de 67,1 millones de usuarios únicos entre los lectores de $\mathrm{EI}$ País (19,1 millones), El Mundo (18,4 millones), La 
Vanguardia (14,9 millones) y $\mathrm{ABC}$ (14,7 millones). En conjunto cubren casi el $50 \%$ de la audiencia de medios digitales de información general del país.

La información relevante se clasificó en distintas categorías de análisis. Las unidades de análisis fueron las piezas informativas editadas por los medios digitales e identificadas por una URL y un espacio propio en la web de cada diario.

Los contenidos analizados fueron recursos de naturaleza escrita (posts, referencias procedentes de redes sociales incluidas en el texto de las informaciones), gráfica (imágenes), audiovisual (vídeos) e híbrida (posts con fotografías, posts con vídeos).

Las variables analizadas fueron tres: "contenidos informativos de redes sociales", "área temática informativa" y "géneros discursivos".

El diseño de la investigación se basó en un modelo unifactorial aplicado al análisis de cada una de las variables $(1 \times 1)$. Para la variable "contenidos informativos de redes sociales" se empleó este modelo para examinar las piezas editadas con contenidos de redes sociales en relación con las piezas elaboradas sin ellas. Para la variable "área temática informativa" también se empleó un modelo $1 \times 1$ (piezas con contenidos de redes sociales $X$ área temática informativa). Por último, para la variable "géneros discursivos", se empleó el mismo modelo $1 \times 1$ (piezas con contenidos de redes sociales $X$ género discursivo).

\section{RESULTADOS}

\subsection{Consumo de contenidos informativos de redes sociales: volumen de noticias}

La primera variable de la investigación se analizó, en primer lugar, comparando el número de noticias más leídas por la audiencia que incluían contenidos de redes sociales como fuentes de información alternativas y el número de noticias elaboradas solo con fuentes tradicionales.

Estos fueron los resultados registrados

\section{Noticias más leídas por la audiencia}

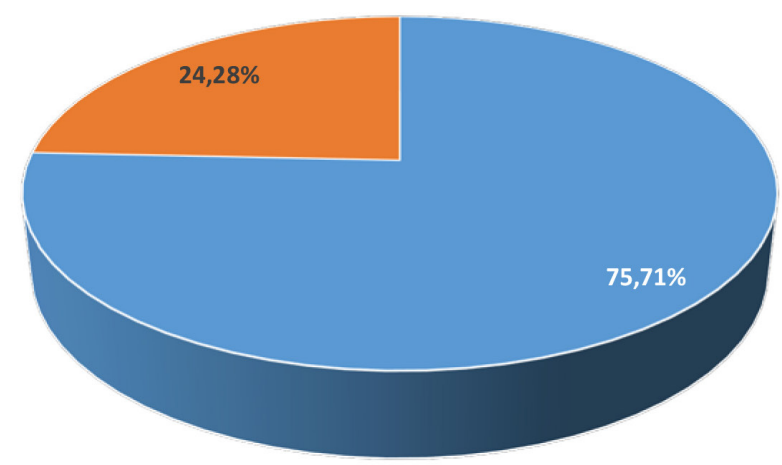

Gráfico $n^{0} 1$. Noticias con y sin contenidos de redes sociales más leídas por la audiencia (cómputo global). Fuente: elaboración propia. 
En términos generales, la audiencia consumió un mayor volumen de noticias que no incluyeron contenidos de redes sociales $(75,71 \%$ del total de piezas informativas). Las noticias elaboradas solo con fuentes de información tradicionales (documentales, informaciones de agencia, declaraciones de testigos o sujetos de la información obtenidas por los reporteros o redactores, etc.) fueron mucho más numerosas en el ranquin de las noticias más vistas por los lectores.
El análisis de la variable "contenidos informativos de redes sociales" también se analizó en función de cada medio de comunicación de referencia. La finalidad era comprobar si existen diferencias marcadas entre las audiencias de cada medio digital en el consumo de este tipo de información en la actual situación de fragmentación de audiencias.

Los datos se exponen a continuación:

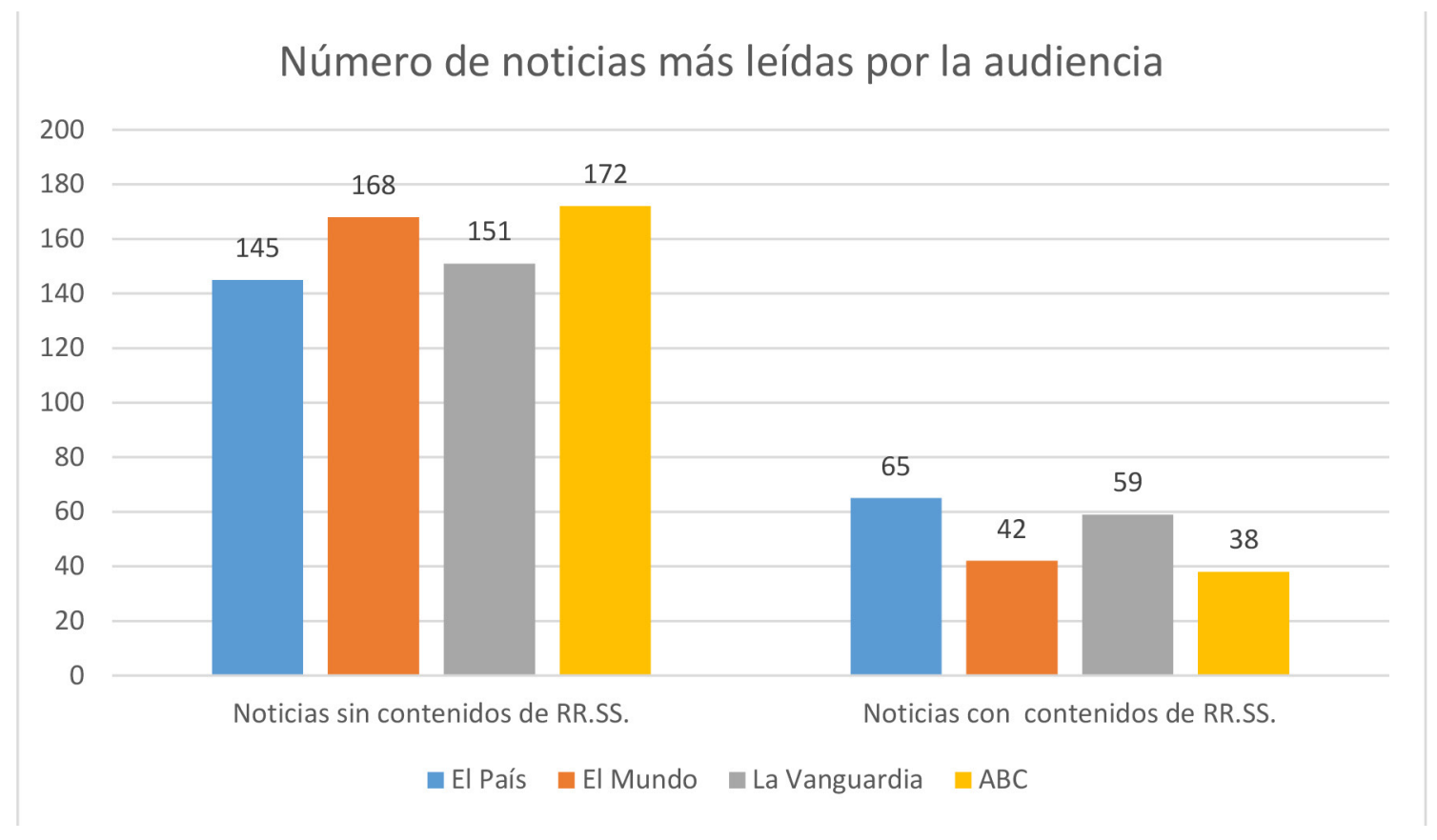

Gráfico $n^{\circ}$ 2. Noticias con y sin contenidos de redes sociales más leídas por la audiencia en cada diario digital. Fuente: elaboración propia.

El consumo de noticias que incluyen este tipo de contenidos puede describirse como bastante homogéneo en todos los medios. No obstante, se advierten diferencias indicativas de ciertas tendencias editoriales: mientras que las audiencias de El País y La Vanguardia consumen en mayor medida este tipo de contenidos, los lectores de El Mundo y ABC se muestran más reacios.
A continuación, tomando como referencia el $24,28 \%$ de noticias que incluyeron contenidos de redes sociales, se calculó el número de noticias editadas exclusivamente con información escrita, gráfica o audiovisual procedente de perfiles o cuentas de usuarios de redes sociales, incluidas en el ranquin de las más leídas. Por tanto, se excluyeron del análisis, todas aquellas noticias que incluían al mismo tiempo 
contenidos de redes sociales y otras fuentes de información tradicionales. El objetivo era conocer la valoración de la audiencia respecto a noticias cuya única fuente de información fueron contenidos de redes sociales.
Las noticias que incluyeron este tipo de contenidos como única fuente informativa representaron el $16,41 \%$, frente al $83,58 \%$ de noticias que incluyeron este tipo de fuente además de las tradicionales. Así se repartió ese bajo porcentaje entre los cuatro diarios digitales analizados:

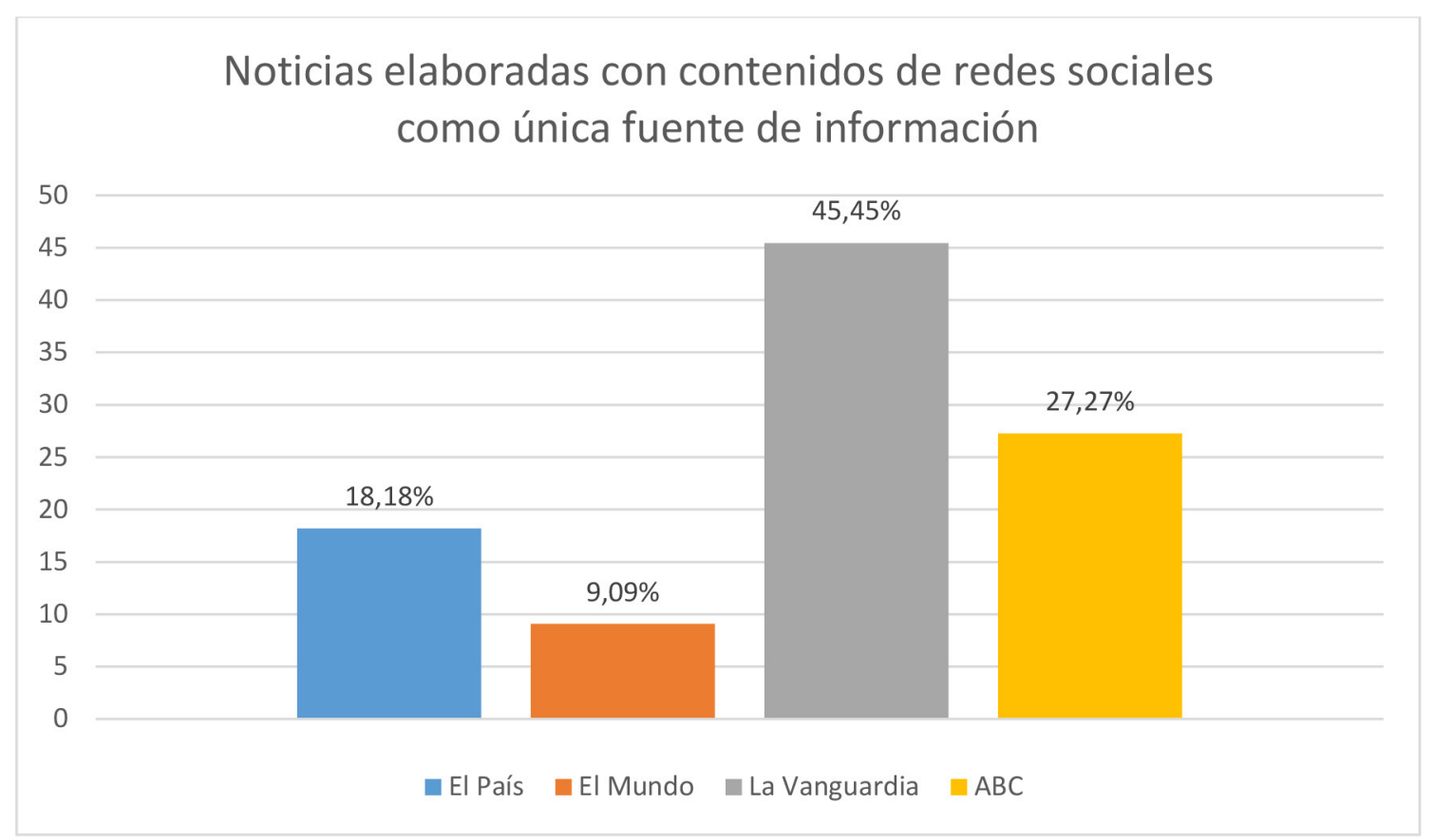

Gráfico $n^{\circ}$ 3. Noticias más leídas elaboradas con contenidos de redes sociales como única fuente informativa. Fuente: elaboración propia.

Una vez más, la audiencia, globalmente calculada, leyó en menor medida las informaciones elaboradas solo con contenidos de redes sociales. El porcentaje alcanzado fue bajo en relación con el total de piezas que incorporaron contenidos de redes sociales y otras fuentes de información periodística.

También en este aspecto se aprecian diferencias entre las audiencias de los distintos medios analizados. Los lectores del diario $A B C$, los que estadísticamente menos noticias con contenidos de redes sociales visitaron, fueron paradójicamente los segundos que más consumieron este tipo de contenidos cuando fueron empleados como única fuente de información en las noticias. Las diferencias registradas entre las audiencias de El País y La Vanguardia, medios en principio algo más afines entre sí, también fueron notables en esta categoría de noticias.

\subsection{Consumo semanal de contenidos informativos de redes sociales}

El consumo de contenidos informativos de redes sociales se analizó también en función del factor tiempo. Por un lado, se calculó el consumo de noticias con contenidos de redes sociales registrado entre 
semana (lunes a viernes) y por otro, los fines de semana (sábado y domingo). Se pretendió examinar el comportamiento de la audiencia frente a los cambios en la producción periodística introducidos por los editores de los medios de comunicación. Como es sabido, las temáticas y los géneros periodísticos son otros en las ediciones de fin de semana. En esos días los medios digitales suelen dedicar un espacio mayor a los reportajes y artículos de opinión y menos a los temas de estricta actualidad.
El registro de las noticias más leídas por los públicos se efectuó en cada medio al final de la jornada, de lunes a domingo, con el fin evitar sesgos horarios que pudieran influir en los resultados finales. También se eligió este horario para evitar las fluctuaciones en el ranquin provocadas por las urgencias informativas de cada día y que son las que marcan el ritmo de la actualidad.

El consumo de noticias con contenidos de redes sociales a lo largo de la semana se refleja en los siguientes gráficos:

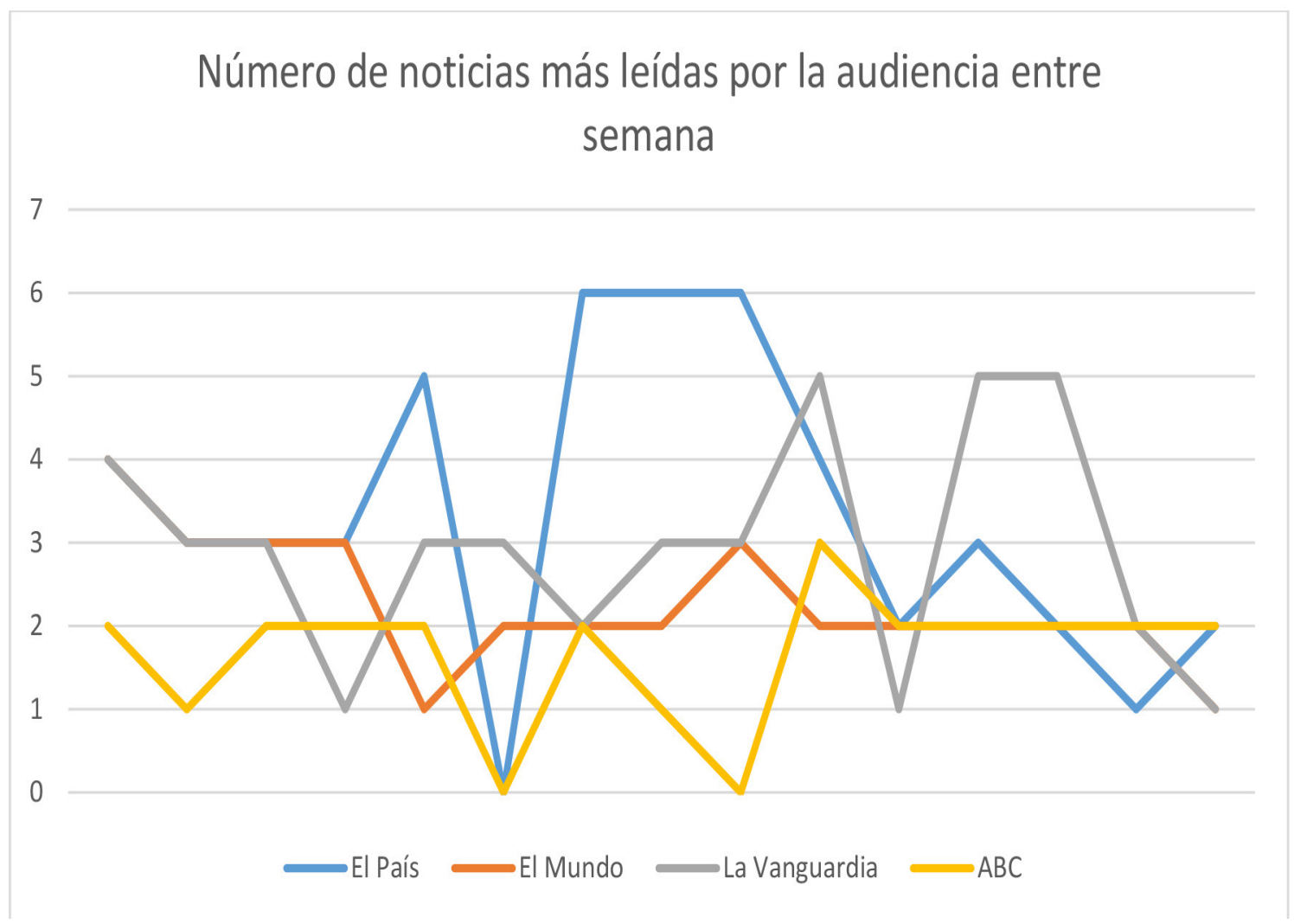

Gráfico $n^{\circ} 4$. Número de noticias con contenidos de redes sociales más leídas por la audiencia en cada medio (lunes a viernes) entre los días 8 y 26 de enero de 2018. Fuente: elaboración propia. 


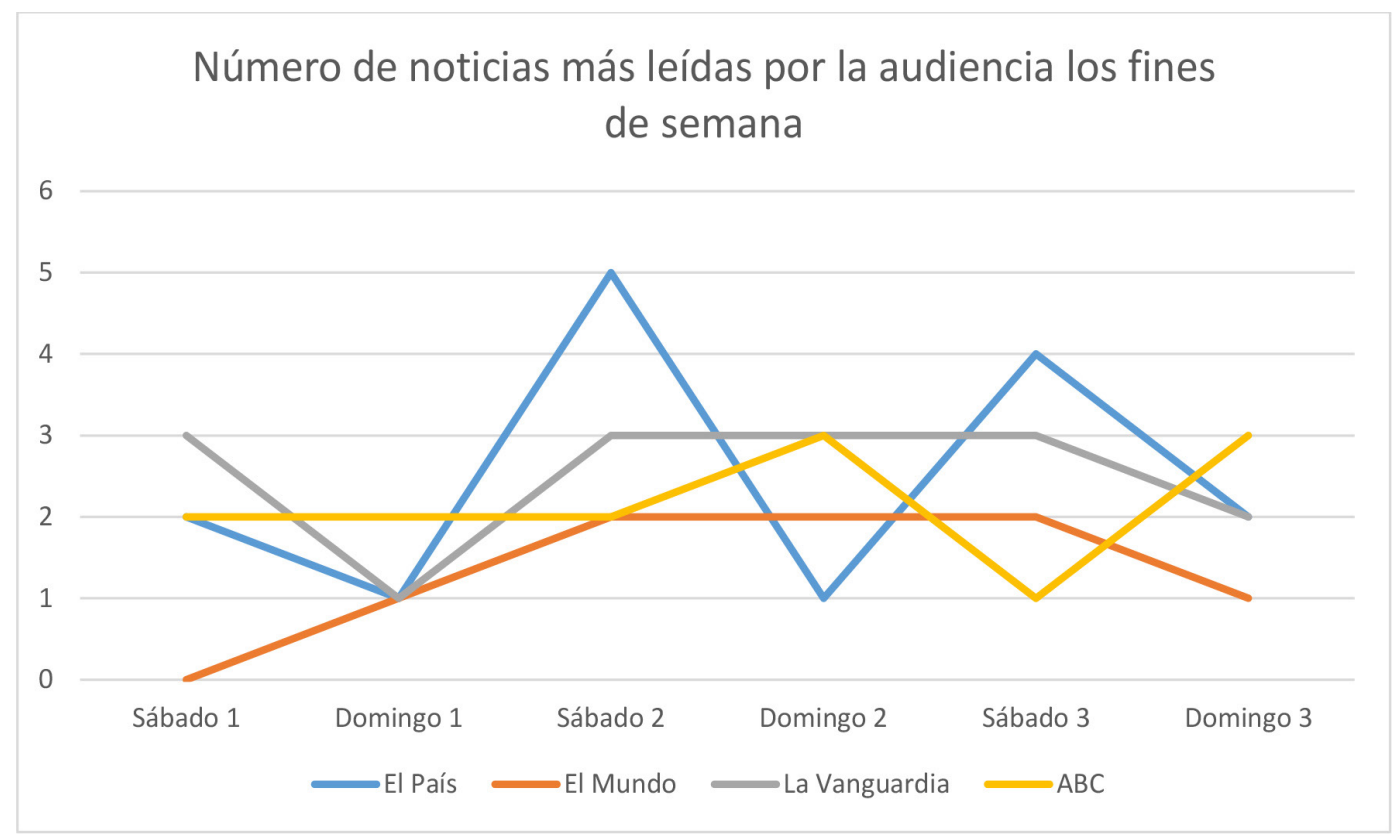

Gráfico $n^{\circ} 5$. Número de noticias con contenidos de redes sociales más leídas por la audiencia en cada medio (fines de semana) entre los días 13 y 28 de enero de 2018. Fuente: elaboración propia.

De lunes a viernes se registró el mayor número de noticias que incorporaron contenidos de redes sociales en todos los diarios analizados. El número medio diario de noticias leídas por los lectores (de lunes a viernes) fue de 2,54. Superaron esta media El País con 3,33 noticias al día leídas por la audiencia y La Vanguardia con 2,93 noticias. El Mundo $(2,26$ noticias) y $A B C$ (1,66 noticias) estuvieron por debajo. Los fines de semana el consumo de noticias con contenidos de redes sociales disminuyó en los cuatro diarios digitales analizados. El número medio de noticias leídas fue de 2,12, aunque cada medio registró medias por encima y por debajo de esta cifra: El País y La Vanguardia igualados con 2,5 noticias, $A B C$, con 2,16 noticias y, por último, El Mundo con una media de 1,33 noticias leídas los fines de semana. El consumo a la baja se detectó en todos los medios excepto en el diario $A B C$, cuya audiencia consumió más noticias con contenidos de redes sociales el fin de semana que entre semana.

Podría intuirse que la causa del menor consumo de piezas informativas con contenidos de redes sociales se debe a la presencia de productos informativos de fin de semana, menos propicios a la inclusión de contenidos generados por los usuarios (artículos de opinión, tribunas, análisis, reportajes de fondo, etc.). Pero lo cierto es que estos géneros apenas figuraron entre las noticias más visitadas. Se observó, además, que al disminuir los fines de semana el número de noticias de estricta actualidad, fueron desapareciendo proporcionalmente del ranquin las informaciones elaboradas con contenidos de redes sociales. Los resultados parecen sugerir una tendencia hacia un mayor consumo de contenidos de redes sociales incluidos en las noticias de actualidad. 


\subsection{La producción de contenidos informativos} de redes sociales: áreas temáticas

La variable "área temática informativa" se analizó en la investigación en relación con dos categorías de noticias: las que incorporaban fuentes de información de redes sociales y tradicionales al mismo tiempo, y aquellas que solo incluían contenidos de redes sociales como única fuente de información. Se trataba de conocer en qué áreas informativas aparecen con mayor frecuencia los contenidos generados en las redes sociales y que son consumidos por la audiencia. A continuación se exponen los resultados registrados en la primera categoría de noticias:

\section{Áreas informativas}

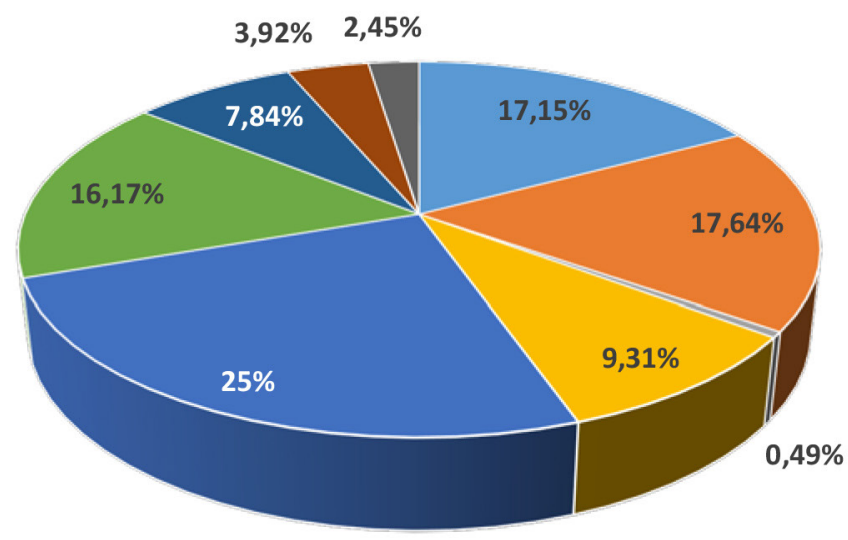

$$
\begin{aligned}
& \text { - Internacional - Nacional =Economía = Sucesos - Crónica social } \\
& \text { - Sociedad - Cultura - Deportes - Otras }
\end{aligned}
$$

Gráfico $n^{\circ} 6$. Áreas informativas a las que pertenecen las noticias con contenidos de redes sociales más leídas por la audiencia. Fuente: elaboración propia.

Prácticamente todas las áreas informativas obtuvieron representación entre las noticias más leídas por la audiencia. De forma marginal se registraron noticias sobre las siguientes áreas temáticas: viajes, tecnología, información meteorológica y ciencia, que representaron un $2,45 \%$ del total.

Los resultados globales señalan un equilibrio entre las noticias con temática más compleja o hard news (internacional, nacional, economía y sucesos $-44,59 \%$ ) y aquellas con contenidos más accesibles para el gran público o soft news (crónica social, sociedad, deportes y cultura $-55,38 \%-)$.

Sin embargo, el área temática que incluye el mayor número de noticias consultadas por la audiencia en términos específicos fue la crónica social (25\%). En esta categoría de noticias se publicaron informaciones centradas en la crónica rosa y en celebridades, de cuyos perfiles en redes sociales los medios obtienen recursos informativos y gráficos con mayor eficacia que otras fuentes. 
Los resultados indican una presencia relativamente homogénea de contenidos de redes sociales repartidos a lo largo de todo el espectro temático, aunque se advierte un relativo incremento del número de contenidos propios de soft news (crónica social). Las noticias que permanecieron dos días consecutivos o más en el ranquin de las más leídas solo representaron el $18,13 \%$ del total de noticias y pertenecieron a las siguientes áreas informativas: sociedad $(40,54 \%)$, crónica social $(21,62 \%)$, internacional $(16,21 \%)$, nacional $(13,51 \%)$, cultura $(5,40 \%)$ y sucesos $(2,70 \%)$.
El total de áreas temáticas propias de soft news alcanzó el $67,56 \%$ en esta categoría de noticias, mientras que los temas más habituales en hard news representaron un minoritario $32,42 \%$. De nuevo, son los temas asociados a las noticias más ligeras los que predominan en esta categoría de informaciones y por un período de tiempo mayor, más allá del criterio estricto de la actualidad.

El análisis de las áreas temáticas se efectuó asimismo en los cuatro medios de referencia de la investigación:

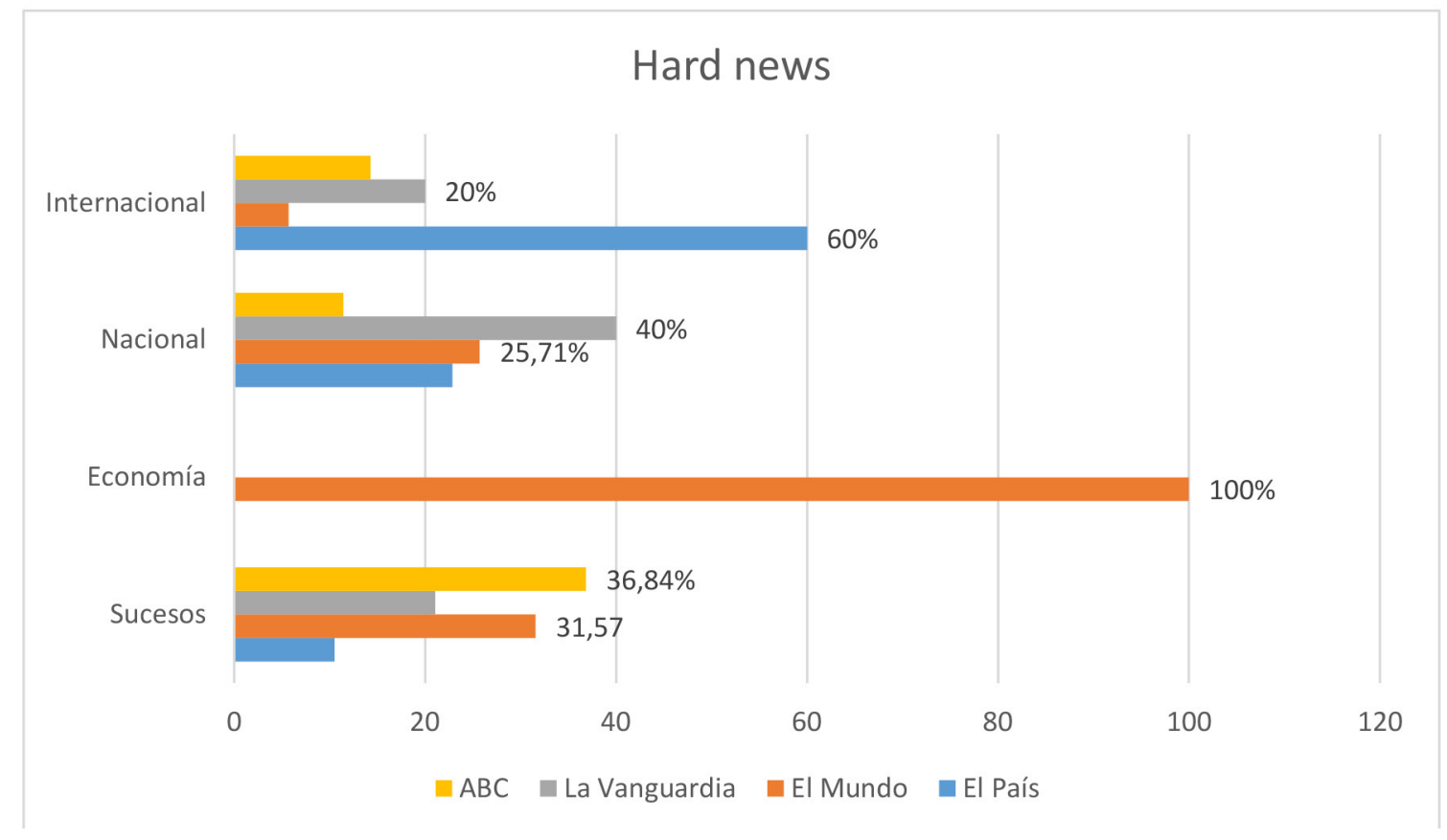

Gráfico $n^{\circ} 7$. Áreas informativas de las noticias con contenidos de redes sociales más leídas por la audiencia en cada medio (hard news). Fuente: elaboración propia.

En términos absolutos, los resultados relativos a Así, El País destacó por ser el diario más leído en temáticas propias de hard news fueron los siguientes: El Mundo (40,74\%); El País (23,34\%); La Vanguardia informaciones de temática internacional elaboradas $(20,26 \%)$ y $A B C(15,63 \%)$. con recursos procedentes de redes sociales (60\%). El Sin embargo, los resultados desglosados en función de resultado podría explicarse si se tiene en cuenta que cada medio arrojan importantes diferencias editoriales. El País es un medio de comunicación más proclive que el resto a incluir este tipo de contenidos en las 
informaciones que publica en su sección internacional. El porcentaje que esta área informativa representó en las noticias de los demás diarios fue el siguiente: La Vanguardia: $20 \%$, ABC: $14,28 \%$ y El Mundo: $5,71 \%$.

En las noticias de temática nacional, La Vanguardia fue el medio que más noticias con contenidos de redes sociales (post escritos o tuits de políticos y fotografías, fundamentalmente) consultó la audiencia (40\%). El Mundo obtuvo un porcentaje de $25,71 \%$, El País de $22,85 \%$ y $A B C$ de $11,42 \%$.
El Mundo fue el diario leído por el $100 \%$ de la audiencia en las informaciones de naturaleza económica publicadas por los medios.

Las noticias de sucesos suscitaron el interés de la audiencia en menor medida. $A B C$ fue el medio más seguido $(36,84 \%)$ en esta área informativa; le siguieron El Mundo (31,57\%), La Vanguardia (21,05\%) y finalmente, El País (10,52\%).

Los resultados de las áreas informativas sobre las que habitualmente versan las soft news son los siguientes:

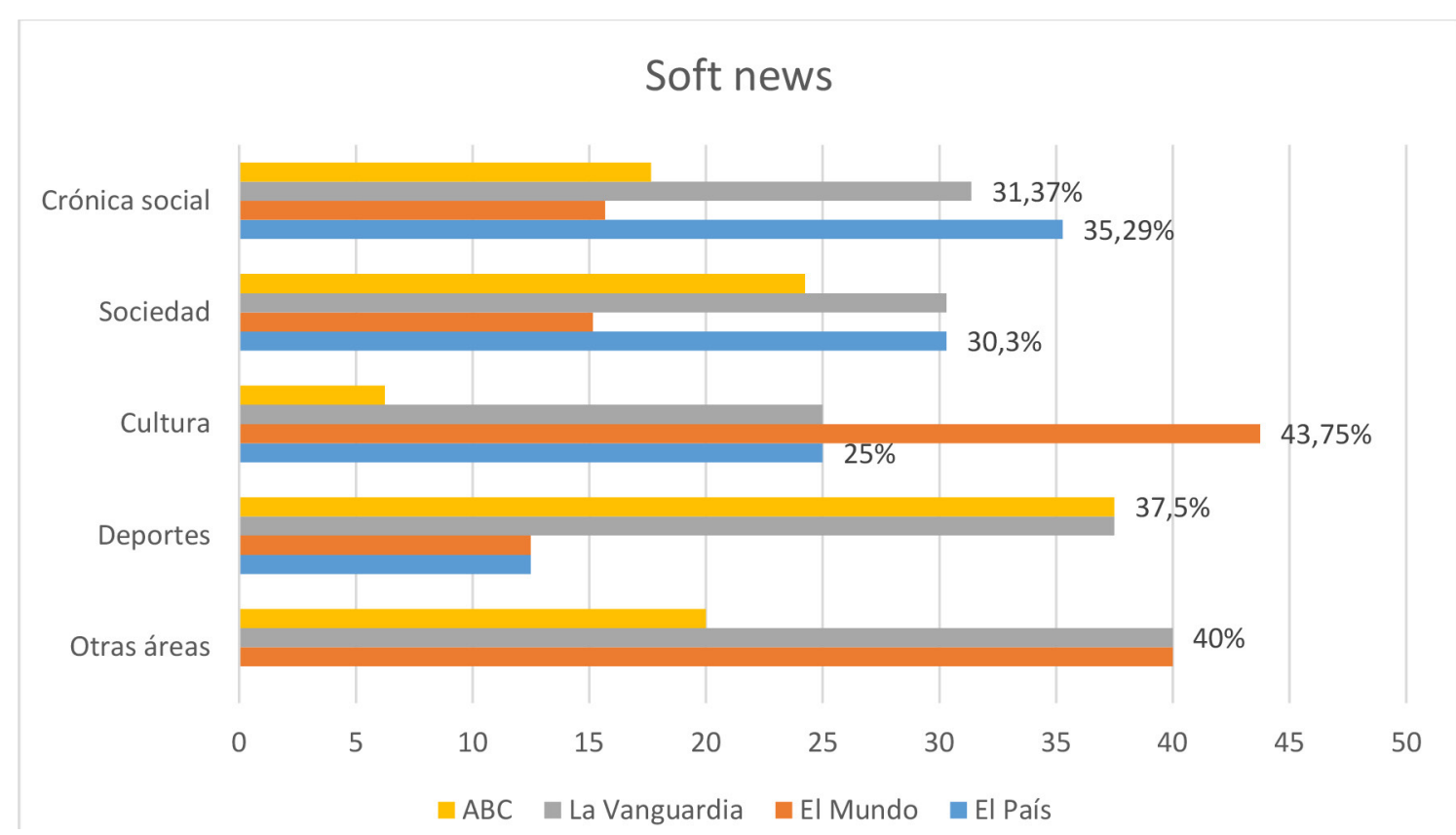

Gráfico n 8. Áreas informativas de las noticias con contenidos de redes sociales más leídas por la audiencia en cada medio (soft news). Fuente: elaboración propia.

Las noticias pertenecientes a la categoría de soft news obtuvieron una representación más homogénea. Los medios más leídos por la audiencia en términos globales fueron por este orden: La Vanguardia $(32,83 \%)$, El Mundo $(25,41 \%)$, ABC $(21,12 \%)$ y El País (20,61\%).
La Vanguardia y El País destacaron en los asuntos de sociedad y crónica social. También fueron los segundos respecto a la información cultural. Además, La Vanguardia fue el diario más leído en la sección de deportes (igualado con $A B C$ ) $-37,5 \%$ - y otras áreas como viajes, ciencia y tecnología e información meteorológica. 
Las noticias culturales de El Mundo elaboradas con contenidos de redes sociales fueron las más vistas por la audiencia con una notable diferencia $(43,75 \%)$ respecto a los demás medios. También fue este el diario más leído en secciones informativas minoritarias ("otras áreas").

$A B C$ y El Mundo fueron las opciones minoritarias respecto a la crónica social $(17,64 \%$ y $15,68 \%$, respectivamente). También lo fueron respecto a las noticias de sociedad $(24,24 \%$ y $15,15 \%)$.

$A B C$ fue el medio menos leído en lo que respecta a la información cultural $(6,25 \%)$. También ocuparon esta posición El Mundo y El País respecto a la información deportiva (12,5\% en ambos casos). El País no registró datos de audiencia en relación con las áreas minoritarias analizadas en la investigación (viajes, tecnología, ciencia e información meteorológica). En esta sección miscelánea $A B C$ ostentó un porcentaje de representación del $20 \%$.

Las noticias que incluyeron contenidos de redes sociales como única fuente informativa se analizaron también en función de la variable "área temática informativa". Los resultados se exponen en el siguiente gráfico:

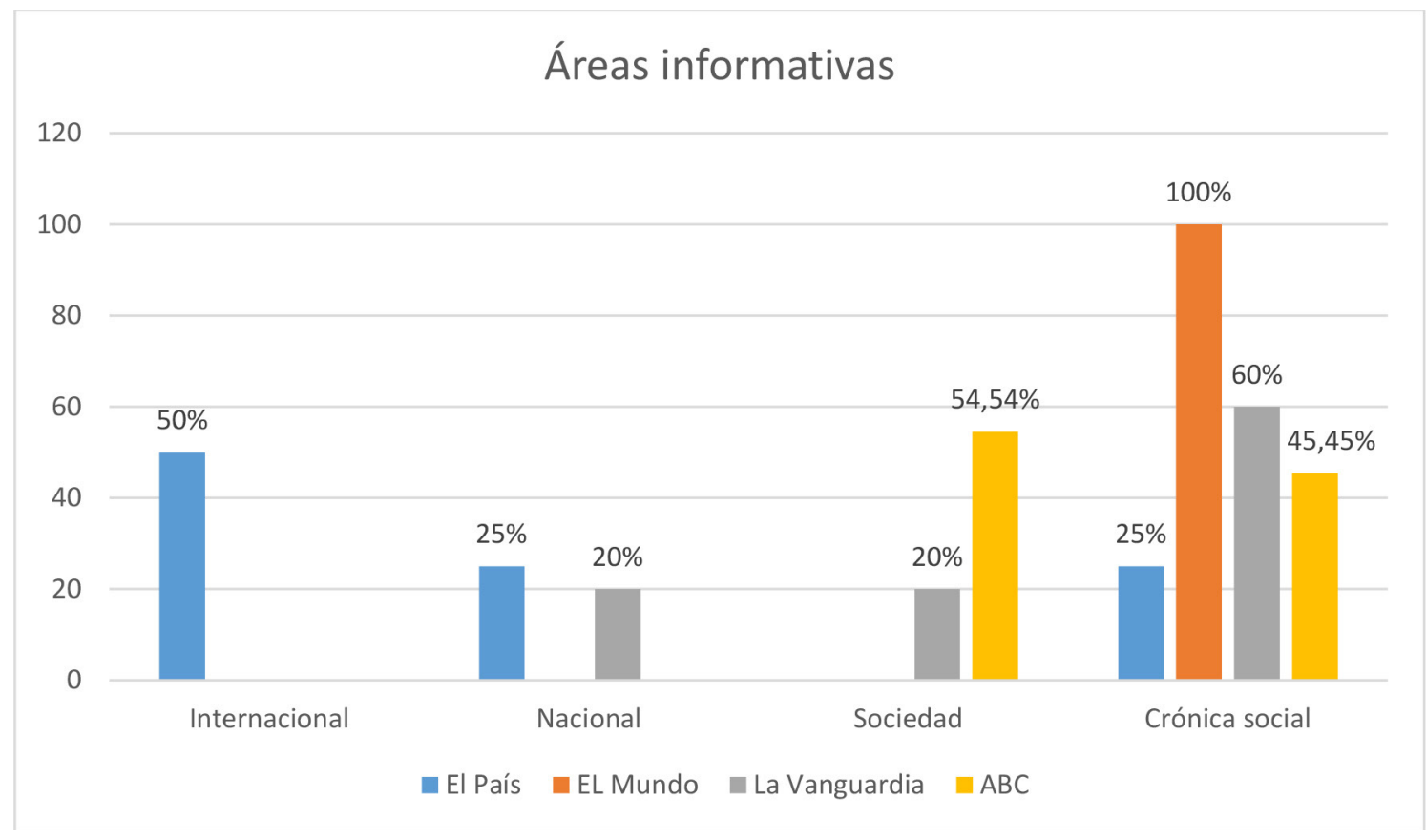

Gráfico $n^{\circ} 9$. Áreas informativas a las que pertenecen las noticias con contenidos de redes sociales como única fuente informativa. Fuente: elaboración propia.

El área temática más representada fue la crónica social, que fue la más leída por más de la mitad de la audiencia global de los cuatro diarios digitales analizados $(51,85 \%)$. Le siguieron las noticias del área de sociedad $(29,62 \%)$, nacional $(11,11 \%)$ e internacional $(7,40 \%)$. Se repite en esta categoría $(18,51 \%)$ y de soft news $(81,47 \%)$. 
La crónica social de El Mundo ( $100 \%$ de sus noticias) y de La Vanguardia (60\%) fueron las más leídas. ABC y La Vanguardia fueron los únicos medios a los que acudió la audiencia para leer noticias de sociedad. Ambas áreas informativas obtuvieron un porcentaje de representación notablemente mayor cuando se incluyeron en las noticias contenidos de redes sociales como única fuente informativa en relación con las piezas que también incluyeron fuentes de información tradicionales.

Las noticias más vistas por la audiencia en estas dos áreas mayoritarias incluyeron fuentes de información de acceso exclusivo o más rápido a través de redes sociales. Algunos ejemplos de estas noticias fueron las historias de vida ("La carta de la madre de un niño autista desamparado en un colegio de Valencia que emociona a Facebook" publicada por el diario ABC el 26.01.2018; "Las lecciones de vida que dejó por escrito en Facebook una joven víctima del cáncer" publicada el 10.01.2018 por La Vanguardia) o material de carácter privado publicado por celebridades en sus perfiles sociales ("Chris Hemsworth y Elsa Pataky publican el mismo vídeo de su hijo, pero a él le ríen la gracia y a ella la critican" publicada por El País el 09.01.2018).

\subsection{Contenidos informativos de redes sociales y géneros periodísticos}

La variable "géneros periodísticos" se analizó en relación con los géneros discursivos que se registraron en las noticias con contenidos de redes sociales más leídas por la audiencia. Estos fueron: noticias, reportajes, crónicas, entrevistas y fotogalerías. En esta última categoría se incluyeron a los fotoreportajes y a las fotocrónicas (ambos ilustrados con un carrusel de recursos gráficos procedentes de redes sociales). A continuación se presentan los resultados distribuidos en el siguiente gráfico:

\section{Géneros discursivos}

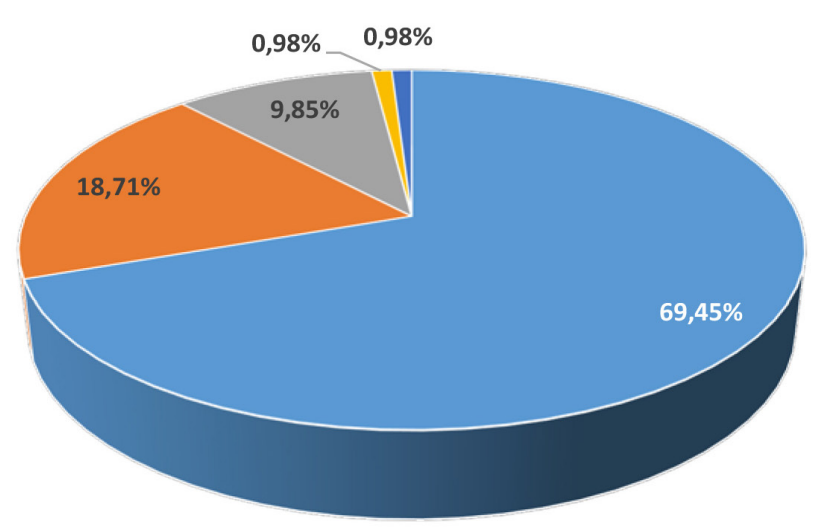

- Noticias " Reportajes " Crónicas " Entrevistas - Fotogalerías

Gráfico n 10. Géneros discursivos en las noticias con contenidos de redes sociales. Fuente: elaboración propia.

El análisis de los géneros periodísticos se efectuó igualmente en cada diario de referencia: 


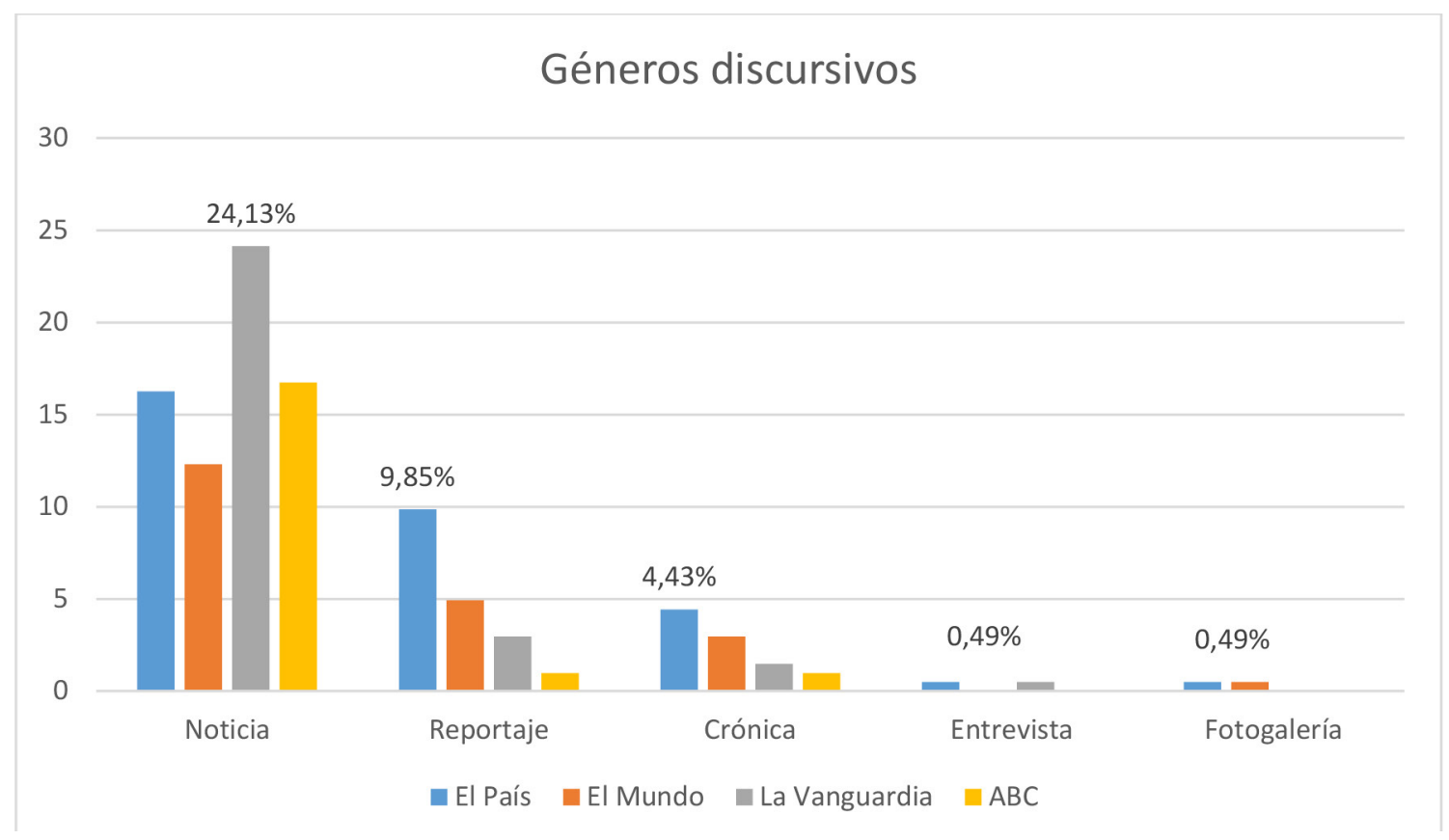

Gráfico n 11. Géneros discursivos en las noticias con contenidos de redes sociales en cada medio. Fuente: elaboración propia.

El género de la noticia fue predominante $(69,45 \%)$, seguido a gran distancia por el reportaje $(18,71 \%)$ y la crónica $(9,85 \%)$. Las entrevistas fueron un género representado en un porcentaje sensiblemente inferior. Resulta significativa la escasa presencia de los géneros más próximos o similares a los que la audiencia consume en las redes sociales, en particular, las fotogalerías (en la investigación solo se registraron un fotoreportaje y una fotocrónica).

El estudio comparado de medios arrojó resultados relativamente homogéneos. Las noticias de La Vanguardia fueron las más leídas por la audiencia. El $24,13 \%$ del total de piezas informativas más vistas por los lectores fueron noticias editadas por ese diario digital. El País ocupó la segunda posición (16,25\%), ABC la tercera $(16,74 \%)$ y EI Mundo la última posición $(12,31 \%)$.
Los lectores de EI País fueron los que más accedieron a sus reportajes editados con contenidos de redes sociales $(9,85 \%)$. Tras ese diario se posicionan El Mundo (4,92\%), La Vanguardia (2,95\%) y ABC $(0,98 \%)$.

Las crónicas de El País (4,43\%) y El Mundo (2,95\%) también destacaron entre las más vistas por la audiencia. La Vanguardia ocupa la tercera posición $(1,47 \%)$ y por último se sitúa el diario $A B C(0,98 \%)$.

En términos generales, La Vanguardia destacó como el medio más leído cuando publicó noticias que incluyeron contenidos de redes sociales. El País y EI Mundo lo fueron respecto a los géneros interpretativos elaborados con información procedente de las redes sociales. 


\section{DISCUSIÓN}

Los resultados de la investigación dan respuesta a las hipótesis planteadas, confirmando en unos casos y matizando en otros las presunciones manifestadas sobre la producción y consumo de información digital elaborada con contenidos de redes sociales. Por otra parte, la naturaleza exploratoria de la investigación hace necesario poner en relación sus hallazgos con los de otros trabajos llevados a cabo por la doctrina en relación con medios de comunicación análogos y desde perspectivas complementarias.

Los resultados registrados sobre el volumen de noticias con contenidos de redes sociales más leídas por la audiencia indican la existencia de un patrón similar al existente en los medios escritos. Los resultados de la investigación coinciden con los de Paulussen y Harder (2014: 542-551) respecto al bajo porcentaje de noticias que incluyen contenidos de redes sociales en la prensa escrita. En ese sentido parece darse una relación bastante ajustada entre la producción periodística y el consumo de información por la audiencia.

No obstante lo anterior, es preciso tener en cuenta las diferencias existentes entre los medios analizados y sus respectivas audiencias (prensa escrita vs prensa digital). Los resultados de la investigación solo podrían compararse con el estudio desarrollado por Herrero (2013: 453-470), aunque no coincidan respecto al volumen de noticias que incluyen contenidos procedentes de redes sociales (80\% frente al escaso $24,28 \%$ registrado en la investigación). De igual modo, es necesario poner en contexto a ambos estudios, ya que el llevado a cabo por Herrero se centró en un caso concreto de sucesos y la presente investigación analiza una muestra más amplia de noticias pertenecientes a distintas áreas informativas. Los datos sobre las áreas informativas analizadas en la investigación también revelan semejanzas con los estudios de Broersma y Graham (2013: 446-464) sobre el uso regular de contenidos de redes sociales en la prensa escrita, tanto en hard news como en soft news. La investigación practicada en España revela una representación mayoritaria de áreas temáticas mas propias de las soft news $(55,38 \%)$, aunque no se aprecia un gran margen de diferencia respecto a las hard news $(44,59 \%)$. El estudio de Broersma y Graham (2013: 453-455) comprobó que el 43\% de las noticias con contenidos generados por los usuarios de las redes sociales pertenecían temáticamente a la categoría de soft news.

La investigación aporta datos estadísticos sobre los géneros periodísticos más presentes en las informaciones elaboradas con contenidos de redes sociales. Los resultados coinciden de forma evidente con los registrados tanto en un estudio de caso en medios digitales por Herrero (2013: 460) como en la prensa escrita por Bacallao (2010: 114-125). En todas las investigaciones practicadas el género informativo de la noticia fue hegemónico respecto al resto de géneros interpretativos y de opinión. Los resultados, aunque coincidentes, deben ser analizados teniendo en cuenta, una vez más, las diferencias entre medios. En el análisis de las variables de la investigación es preciso tener en cuenta ciertas limitaciones propias de un estudio exploratorio como el que se ha emprendido. Por un lado, la investigación ha utilizado una metodología idéntica a la empleada en estudios previos sobre la prensa escrita con el fin de garantizar el mayor grado posible de fiabilidad de los resultados. 
También se ha intentado aislar en la medida de lo posible las variables analizadas respetando un mismo horario de registro y escogiendo un período informativo neutro, no influido por las fluctuaciones de la agenda setting.

A pesar de ello, y principalmente en lo que respecta al consumo de información, queda fuera del alcance de esta investigación analizar todos los factores que son susceptibles de influir en la audiencia como pueden ser los intereses personales o las llamadas de atención de los medios (titulares llamativos, imágenes de impacto, colocación de las noticias en lugares estratégicos, etc.). El análisis de esas y otras variables podría contribuir a configurar una imagen más completa del consumo de noticias elaboradas con contenidos de redes sociales en futuras investigaciones.

\section{CONCLUSIONES}

La audiencia de medios digitales consume información elaborada con contenidos de redes sociales de forma moderada. Solo el $24,28 \%$ del total de noticias más leídas en la prensa digital incluye este tipo de contenidos informativos. $\mathrm{Y}$ de ese porcentaje, un escaso $16,41 \%$ son informaciones elaboradas con estos recursos como única fuente de información. La audiencia de los diarios El País y La Vanguardia fue la más proclive a consumir esta categoría de noticias. En el extremo de la clasificación se sitúa el diario $A B C$. El consumo de informaciones con contenidos de redes sociales no es extensivo, ni entre semana ni durante los fines de semana. El número medio de noticias leídas por la audiencia fue de 2,54 de lunes a viernes y de 2,12 los sábados y domingos. De nuevo El País y La Vanguardia superaron esta cifra, manifestándose como los medios cuya audiencia lee más noticias con contenidos informativos de redes sociales. El diario $A B C$ es el único cuyos lectores muestran un comportamiento menos homogéneo, al aumentar su consumo de contenidos de redes sociales los fines de semana, incidiendo en aquellas noticias que además los utilizan como única fuente de información periodística.

Se advierte en la producción periodística analizada un mayor volumen de contenidos de redes sociales propios de soft news. La crónica social fue el área informativa que alcanzó el mayor porcentaje de representación (25\%) entre todas las áreas analizadas. Además, el $67,56 \%$ de las noticias que se mantuvieron dos o más días entre las más leídas pertenecían a áreas temáticas asociadas a las soft news. Sin embargo, es preciso señalar que, en términos generales, las áreas temáticas de las piezas informativas más leídas se reparten de forma equilibrada entre las hard news, de temática más compleja, y las soft news. Las áreas de nacional, internacional, economía y sucesos representaron el $44,59 \%$ del total, frente al 55,38\% de las secciones de información cultural, sociedad, crónica social, deportes, viajes, ciencia y tecnología y meteorología.

Los lectores de El País fueron los que más noticias internacionales y de sociedad leyeron con contenidos de redes sociales. Los de El Mundo prefirieron la información económica y cultural. La Vanguardia fue el medio favorito para informarse de la crónica social y los asuntos nacionales y $A B C$ fue el más elegido para consultar las crónicas de sucesos. Los datos revelan la influencia de las respectivas líneas editoriales en el consumo de los lectores de prensa digital. Esta circunstancia estaría indicando la ausencia de diferencias significativas en las audiencias a la hora de 
consumir contenidos informativos de redes sociales en relación con el resto de noticias.

Los géneros informativos fueron los más habituales en las noticias con contenidos de redes sociales más leídas de los cuatro diarios digitales analizados. EI género de la noticia $(69,45 \%)$ fue el más frecuente, seguido por el reportaje $(18,71 \%)$ y la crónica $(9,85 \%)$. Las entrevistas fueron un género marginal $(0,49 \%)$, al igual que otros como las fotogalerías, que han surgido en las redes sociales y que, sin embargo, no figuraron entre los más consultados por los lectores $(0,49 \%)$. En ese sentido, la audiencia parece expresar una tendencia a permanecer informada a través de géneros periodísticos tradicionales que, en todo caso, incorporan contenidos de redes sociales. Las noticias de La Vanguardia fueron las más leídas por la audiencia, mientras los reportajes y las crónicas de El País lo fueron en la categoría de géneros interpretativos.

\section{REFERENCIAS}

Aguirre, J. M. (2007). Reinventar la actualidad: los medios digitales y la transformación de las audiencias. En Espéculo. Revista de estudios literarios 37, 1-13. Disponible en http://www.ucm.es/info/especulo/numero37/actualid.html

AMI. Asociación de Medios de Información (2017). El libro blanco de la información 2017. Asociación de Medios de Información (AMI).

Bacallao, L. M. (2010). Representaciones mediáticas de las redes sociales: un estudio de casos. En Revista Latina de Comunicación Social 65, 114-125.

Broersma, M. \& Graham, T. (2013).Twitter as a news source. How Dutch and British newspapers used tweets in their news coverage, 2007-2011. En Journalism Practice 7(4), 446-464. http://dx.doi.org/10.1080/17512786.2013.80248

Campos, F. (2008). Las redes sociales trastocan los modelos de los medios de comunicación tradicionales. En Revista Latina de Comunicación Social 63, 287-293. Disponible en http://www.revistalatinacs.org/_2008/23_34_Santiago/ Francisco Campos.html

Cobos, T. L. (2010). Twitter como fuente para periodistas latinoamericanos. Razón y Palabra 73. Disponible en http://www. razonypalabra.org.mx/N/N73/ Varia73/33Cobos_V73.pdf

Diezhandino, M. P. (coord.) (2012). El periodista en la encrucijada. Barcelona: Ariel-Fundación Telefónica. 
García-Avilés J.A. y Arias F. (2016). Géneros periodísticos en los formatos visuales de Twitter: una propuesta de tipología. En Textual \& Visual Media 9, 101-132.

García deTorres, E. et al. (2011). El uso de Twitter y Facebook por los medios iberoamericanos. En El Profesional de la Información, 20(6). 611-620. doi: http://dx.doi.org/10.3145/epi. Disponible en http://www.academia.edu/1477639/ El_uso_de_Twitter_y_Facebook_por_los_medios_iberoamericanos

Herrera, S. y Requejo, J.L. (2011). Difundir información, principal uso de los diarios generalistas españoles en Twitter. En Textual \& Visual Media 4, 149-182. Disponible en http://www.textualvisualmedia.com/images/revistas/04/ Difundir\%20informacin.pdf

Herrero, E. (2013). Fuentes periodísticas y redes sociales en las noticias de Marta del Castillo. En Estudios sobre el mensaje periodístico 19(1), 453-470.

Lasorsa, D. L.; Lewis, S.C. \& Holton, A. E. (2012). Normalising Twitter: Journalism Practice in an Emerging Communication Space. En Journalism Studies 13 (1), 19-36. doi:10.1080/1461670X.2011.571825

Masip, P. et al. (2015). Información de actualidad y redes sociales: comportamiento de las audiencias. En El profesional de la información 24(4), 363-370.

Nielsen, R. K. \& Schrøder, K. C. (2014). The relative importance of social media for accessing, finding, and engaging with news: An eight-country cross-media comparison. En Digital Journalism, 2(4), 472-489. doi: $10.1080 / 21670811.2013 .872420$

Noguera, J. M. (2010). Redes sociales como paradigma periodístico. Medios españoles en Facebook. En Revista Latina de Comunicación Social 65, 176-186. Disponible en http://www.revistalatinacs.org/10/art/891_UCAM/13 JM Noguera.html

Nölleke, D.; Grimmer, C. \& Horky, T. (2017). News Sources and Follow-up Communication. En Journalism Practice 11 (4), 509-526. https://doi.org/10.1080/17512786.2015.1125761

Paulussen, S. \& Harder, R. A. (2014). Facebook, Twitter and YouTube as sources in newspaper journalism. En Journalism Practice 8 (5), 542-551. http://dx.doi.org/10.1080/17512786.2014.894327

Pew Research Center (2017). News Use Across Social Media Platforms 2017. Disponible en http://www.journalism. org/2017/09/07/news-use-across-social-media-platforms-2017/

Pew Research Center (2012). State of the News Media 2012. An Annual Report on American Journalism. Disponible en http://www.pewresearch.org/2012/03/19/state-of-the-news-media-2012/

Ríos, C. (2014). Cubriendo el referéndum en Escocia desde redes sociales. Los nuevos géneros periodísticos. Disponible en: http://carmelarios.com/2014/09/22/cubriendo-el-referendum-en-escocia-desde-redes-sociales-los-nuevosgeneros-periodisticos/

Shoemaker, P.J. \& Vos T.P. (2009). Media gatekeeping. En M.B. Salwen y D.W. Stacks (eds.) An integrated approach to communication theory and research (pp. 75-89). Nueva York: Routledge.

Stassen, W. (2010). Your news in 140 characters: exploring the role of social media in journalism. En Global Media Journal African Edition 4 (1), http://dx.doi.org/10.5789/4-1-15 
Sundar, S.S. (2008). Self as source: Agency and customization in interactive media. En Konijn, E., Utz, S., Tanis, M. y Barnes S. (eds.). Mediated interpersonal communication (pp. 58-74). Nueva York: Routledge.

Vara-Miguel, A., Negredo, S. y Amoedo, A. (2017). DigitalNewsReport.es. Center for Internet Studies and Digital Life. Reuters Institute for the Study of Journalism. Universidad de Oxford. Disponible en http://www.digitalnewsreport. es/ 